\title{
Wave process in viscoelastic media using fractional derivatives with non singular kernels
}

MARCO ANTONIO TANECO-HERNANDEZ ${ }^{1}$, J. F. Aguilar ${ }^{2}$, and Bricio Cuahutenago-Barro ${ }^{1}$

${ }^{1}$ Autonomous University of Guerrero

${ }^{2}$ CENIDET

January 22, 2022

\begin{abstract}
In this paper, we consider the equations of motion of a bar, of a given density, infinite in both direction, undergoing longitudinal vibrations under the action of an external load, and a stress-strain relationship using a fractional order differentiation operator with respect to the time variable. We use three types of fractional operators, two non-singular, one with exponential kernel and Mittag-Leffler type kernel. And a singular one with power-law type kernel. We analyze some initial and boundary value problems resulting from the modeling of the aforementioned wave processes in viscoelastic media, using some recent proposals for fractional order derivatives. The fundamental solution of these problems is established, and its moments are calculated.
\end{abstract}

\section{Hosted file}

viscoelasticity-05.pdf available at https://authorea.com/users/456660/articles/553662-waveprocess-in-viscoelastic-media-using-fractional-derivatives-with-non-singular-kernels 